\title{
Oxytocin-enhanced motivational interviewing group therapy for methamphetamine use disorder in men who have sex with men: study protocol for a randomized controlled trial
}

\author{
Christopher S. Stauffer ${ }^{{ }^{*}}$ D, Jenna M. Moschetto ${ }^{2}$, Scott M. McKernan ${ }^{3}$, Elaine Hsiang ${ }^{4}$, Brian Borsari ${ }^{1}$ and
} Joshua D. Woolley ${ }^{1}$

\begin{abstract}
Background: The prevalence of methamphetamine use disorder (MUD) in the United States has risen dramatically in the past four decades and is concentrated in populations such as men who have sex with men (MSM). Despite the public health consequences of MUD, there are no FDA-approved psychopharmacological treatments. Psychosocial treatment alone has been shown to reduce methamphetamine use, but high attrition rates limit treatment efficacy. Promising findings from animal models of MUD using exogenous oxytocin, a social neuropeptide, have set the stage for translational work. Along with unique anti-addiction effects, oxytocin holds a primary role in enhancing social salience and modulating stress. In humans, oxytocin administration, combined with evidence-based psychosocial interventions, may act synergistically to improve addiction treatment outcomes and improve retention rates in current MUD treatment.

Methods/design: We are conducting a randomized, double-blind, placebo-controlled trial of oxytocin-enhanced motivational interviewing group therapy (MIGT). Oxytocin or placebo $40 \mathrm{IU}$ is administered intranasally in conjunction with six, weekly MIGT sessions. We will recruit 50 MSM, initiating treatment for MUD from specialized community health programs in San Francisco, CA, USA. Individuals will be randomized (1:1) to receive six, weekly sessions of MIGT with or without oxytocin. Our primary outcome is session attendance. Other outcomes of interest include: measures of group cohesion, anxiety, psychophysiology, and stimulant craving and use.

Discussion: This will be the first study of oxytocin's effects in humans with MUD. Findings from this novel protocol will attempt to bridge existing animal data with the need for innovative clinical treatments for MUD, inform the growing field of pharmacologically-enhanced psychotherapy, and help to elucidate mechanisms behind oxytocin's potential anti-addiction effects.
\end{abstract}

Trial registration: ClinicalTrials.gov, ID: NCT02881177. Registered on 26 August 2016.

Keywords: Methamphetamine use disorder, Meth, Stimulant, Oxytocin, Men who have sex with men, Motivational interviewing, Group therapy, Addiction, Drug-assisted psychotherapy

\footnotetext{
* Correspondence: christopher.stauffer@ucsf.edu

${ }^{1}$ University of California, San Francisco, San Francisco VA Medical Center, San

Francisco, CA, USA

Full list of author information is available at the end of the article
}

(c) The Author(s). 2019 Open Access This article is distributed under the terms of the Creative Commons Attribution 4.0 International License (http://creativecommons.org/licenses/by/4.0/), which permits unrestricted use, distribution, and reproduction in any medium, provided you give appropriate credit to the original author(s) and the source, provide a link to the Creative Commons license, and indicate if changes were made. The Creative Commons Public Domain Dedication waiver (http://creativecommons.org/publicdomain/zero/1.0/) applies to the data made available in this article, unless otherwise stated. 


\section{Background}

Methamphetamine is a potent psychostimulant with high abuse potential [1]. Methamphetamine and amphetamine-type stimulants are second only to cannabis as the most frequently used illicit substance worldwide [2], and, according to the 2017 Global Drug Survey [3], methamphetamine was the illicit substance most likely to lead to emergency medical treatment seeking. High healthcare utilization contributes to the multifactorial economic burden of methamphetamine, which is estimated to be upwards of US\$23.4 billion in the United States (US) alone (Rand Corporation, 2008). The prevalence of methamphetamine use disorder (MUD) in the US has risen dramatically in the past four decades, with high concentrations among men who have sex with men (MSM) [4-6]. Despite the personal and societal consequences of methamphetamine use, no pharmacological agent currently has an FDA-designated indication to treat MUD [7, 8].

Psychosocial treatment alone has been shown to reduce methamphetamine use and rates of relapse, with a longer duration of treatment producing better results [9-13]. However, methamphetamine users exhibit high attrition rates of $60 \%$ or more, which limits the effectiveness of treatment and leads to missing data and validity issues in clinical research contexts [14]. This complicates efforts to identify pharmacotherapy candidates or to improve evidence-based psychosocial treatments for MUD $[8,15]$. Methamphetamine is associated with impairments in social cognition and theory of mind, including a hypersensitivity to social threat, which likely contribute to reduced treatment adherence and retention [16-19]. Social rehabilitation, often in the form of group and family therapy, is a prominent component of gold-standard psychosocial treatments for MUD [20, 21]. Even in animal models of methamphetamine addiction, socially housedversus individually housed-rats were protected against escalating methamphetamine self-administration [22]. Given the social complexities and challenges surrounding MUD clinical treatment and research, an adjunctive pharmacotherapy that might enhance social cognition and boost engagement and retention in effective psychosocial treatment could greatly improve outcomes [23].

Oxytocin, a hypothalamic peptide that plays a critical role in mammalian attachment and affiliative behavior [24-26], administered exogenously, is a promising candidate as an adjunctive addiction treatment [27, 28]. Oxytocin has unique anti-addiction effects [27, 29] along with social salience [30] and stress-tempering properties [31-33], which together may shift attentional bias toward positive social reward at the expense of conditioned drug-related reward [28, 34]. Oxytocin is a large, hydrophilic molecule, so does not readily cross the blood-brain barrier after peripheral administration. The intranasal route is thus far the most efficient way to deliver oxytocin to the human central nervous system $[35,36]$ and is extremely safe and tolerable [37]. What is more, there are no discernable subjective effects (i.e., research participants cannot typically guess whether they have received oxytocin versus placebo), which allows the use of an inactive placebo [37].

Methamphetamine self-administration in rats has been shown to dysregulate the oxytocin system [38-40], and some evidence for this exists in humans [41]. In animal models of methamphetamine addiction, oxytocin administration reduces the acquisition and increases extinction of compulsive methamphetamine self-administration and reduces stress-primed and drug-primed reinstatement of methamphetamine-seeking behavior [27, 42-47]. In addition, oxytocin administration attenuates methamphetamine tolerance and withdrawal, methamphetamineinduced stereotyped movements, methamphetamine-induced conditioned place preference, and reduces methamphetamine-induced c-Fos expression in areas of the basal ganglia implicated in addiction [44, 48-51]. In humans, oxytocin has demonstrated some efficacy in early trials with alcohol, cannabis, opioid, and cocaine users [52, 53]. To our knowledge, this will be the first study to investigate the effects of intranasally administered oxytocin on the symptoms of MUD in humans.

Oxytocin administration in combination with evidencebased group psychotherapy-oxytocin-enhanced motivat ional interviewing group therapy (OE-MIGT) - may synergistically enhance treatment outcomes and address the notoriously high drop-out rates evident in MUD populations. We aim to investigate the effectiveness of intranasally administered oxytocin on MIGT treatment engagement. Specifically, we hypothesize that oxytocin will increase attendance at treatment sessions. In addition, we will estimate effect sizes and assess procedures used to test oxytocin's effects on group cohesion, anxiety, psychophysiological stress reactivity, and stimulant craving and use for future trials. This novel translational protocol attempts to bridge ample animal data with the need for innovative clinical treatments for MUD.

\section{Methods/design \\ Study design}

This is a randomized, double-blind, placebo-controlled study of OE-MIGT. Specifically, intranasally administered oxytocin or placebo will be administered in conjunction with each of six, weekly, 90-min MIGT sessions.

\section{Motivational interviewing group therapy (MIGT)}

Motivational interviewing (MI) is defined as a "collaborative conversation style for strengthening a person's own motivation and commitment to change" a behavior [54], be it increasing engagement in treatment or 
discontinuing or cutting down methamphetamine use. MI is client-centered; as a result, the client generates any and all treatment goals and the personalized plans for attaining them. When conducting MI in group settings, co-facilitators use MI-consistent techniques (open-ended questions, affirmations, reflections, and summarization) in the context of the spirit of MI (one of collaboration, compassion, acceptance, and evocation) in order to foster healthy interactions among members and co-facilitators that are focused on exploring healthy behavior change. MIGT co-facilitators aim to guide members through four general group phases: (1) Engagement - enlist members to "open up" by involving them in meaningful relationships based in understanding and acceptance, (2) Exploring Perspectives - collaboratively, and strategically, narrow the focus from cohesion-building to members' perspectives about their current situations, (3) Broadening Perspectives - elicit perspectives and ideas about change, motivation to change, and hopes for success, and (4) Moving Into Action - develop specific plans for how to implement change [55]. In this way, MIGT can improve personal recognition of ambivalence, support autonomy, increase motivation and commitment to change, and improve treatment engagement and participation [55].

The MIGT cohorts in this study will consist of two co-facilitators, one will be a licensed psychiatrist and the other will be a mental health trainee ( $\mathrm{PhD}$, PsyD, or psychiatry resident) along with four to six group members. All MIGT sessions will be conducted at the Alliance Health Project in San Francisco, CA, USA. A semi-structured, closed-admission, time-limited (six sessions) OE-MIGT manual for methamphetamine users was developed for this study using guidance from Wagner and Ingersoll (2013) [55]. Included are four brief psychoeducational components for optional use during the first four sessions: stages of change, ambivalence and a decisional balance chart for methamphetamine use, attachment theory and social support, and managing stress. These topics aid in the Engagement and Exploring Perspectives phases of the group, are designed to maximize the effects of intranasally administered oxytocin on MIGT for MUD, and correspond to the specific objectives of this research study. The final two sessions are left unstructured in order to allow more time for Broadening Perspectives and Moving Into Action. Adherence raters will assess session transcripts using motivational interviewing treatment integrity (MITI) 4.2; a coding system designed to measure group facilitators' adherence to MI [56]. Consistent with previous work by the research team, a fidelity checklist reflecting the content of the session will be developed in order to determine whether the intervention was delivered as intended. Prior to participant enrollment, facilitators will receive training from an MI expert to ensure competency $[57,58]$.

\section{Power analysis}

A sample size of 25 per treatment condition will provide us with $>99 \%$ power to detect an effect size comparable to the large between-condition effect size $(d=1.44)$ observed for attendance from our preliminary 3-week trial in cocaine users [53] with a two-tailed alpha $=0.05$. In addition, this sample size will provide $80 \%$ power to detect an effect size of 0.81 or greater.

\section{Setting and study population}

Previous evidence suggests that oxytocin administration may lead to different outcomes based on the gender [59] and sexual orientation [60] of recipients. To control for this, we limited study participation to men who have sex with men (MSM). Fifty MSM who meet the criteria for MUD will be enrolled in the current study. Participants will be recruited from community mental health programs specializing in this clinical population in San Francisco, CA, USA, including the San Francisco AIDS Foundation, the Alliance Health Project, the Positive Health Program HIV/AIDS Clinic, as well as from study flyers posted in the community. Due to the specificity of our patient population, we acknowledge that participants may recognize each other or even belong to the same social circles. While we do not formally measure pre-existing relationships among those assigned to the same therapy cohort, we do take steps to ensure that intimate partners are not assigned to the same therapy cohort by collecting names of intimate partners as well as any community member that each potential participant would not want to be enrolled with in group therapy.

\section{Inclusion and exclusion criteria}

The inclusion criteria are: (1) 18 to 65 years old, (2) male-identified, (3) history of sexual contact with men, (4) meet Diagnostic and Statistical Manual of Mental Disorders, fifth edition (DSM-5) criteria for severe MUD, and (6) considering initiating treatment for MUD or initiated treatment within the past month. Excluded from this study are individuals with: (1) a diagnosis of bipolar I disorder, (2) evidence of opioid use within the past month, (3) severe alcohol use disorder with withdrawal symptoms, (4) suicidal ideation with intent or plan or homicidal ideation within the past 90 days, (5) suicide attempt in the past 6 months, (6) cognitive impairment or behavioral issues precluding participation in group therapy, (7) diseases likely to influence hormonal or neuroendocrine status or taking hormone supplements, (8) conditions preventing nasal spray administration (e.g., nasal obstruction or frequent nose bleeds), and (7) 
allergies to E216, E218, or chlorobutanol hemihydrate (preservatives in nasal spray).

\section{Identification of target sample (eligibility screen)}

Interested individuals will undergo initial screening for eligibility using a brief, structured telephone interview. To determine full eligibility, participants will attend an initial in-person assessment where informed written consent will be obtained by study staff prior to any study procedures. See Fig. 1 for study flow diagram. Sociodemographic variables will be collected by a clinical assessor, including: age, gender identification, sexual orientation using the Kinsey Scale [61], race, education, employment status, annual income, living situation, relationship status, HIV status, medical history, and medications. The subsections of Major Depressive Disorder, Manic Episodes, Alcohol Use Disorder, Substance Use Disorders, and Psychotic Disorders of The Mini International Neuropsychiatric Interview (MINI) 7.0.0 [62] and the Suicide subsection from the Structured Clinical Interview for DSM-5 (SCID-5) [63] will be administered. Participants will provide a urine sample and undergo additional clinical interviews and self-assessment questionnaires at this initial visit. A study clinician will perform a brief medical examination, including examination of the nasal mucosa.

\section{Procedure}

Eligible individuals enrolled in the study will be randomized, using a computer-generated random number sequence, to receive MIGT along with either oxytocin or placebo administration prior to each session. Each member of a specific MIGT cohort will receive the same study drug as the other members of that cohort, and members of each MIGT cohort will receive the same study drug for all six sessions. Blinding procedures will be controlled by Wellspring Compounding Pharmacy (Berkeley, CA, USA).

Previous work has shown that intranasal oxytocin administration begins to have physiological effects within $30 \mathrm{~min}$ and lasts for at least $90 \mathrm{~min}$ [35]. Thirty minutes prior to beginning each MIGT session, the study physician will administer the study drug (Wellspring Compounding Pharmacy, Berkeley, CA, USA) intranasally using a mucosal atomization device (MAD300; Teleflex technologies, Mooresville, NC, USA) attached to a 1-mL Luer-lock syringe. The oxytocin will be prepared as 40 International Units (IU) of oxytocin per $1 \mathrm{~mL}$. Participants will receive $1 \mathrm{~mL}$ total, with $0.5 \mathrm{~mL}$ administered in each nostril using two separate syringes (with $0.06 \mathrm{~mL}$ additional drug in the first syringe to account for the MAD300 dead space). The administration procedures are consistent with recommendations for standardized intranasal drug administration [64]. Study drug administration will occur with all members present in the group therapy space, and the order of administration to individuals within a cohort will be randomized at each session.

To test tolerability to the study drug, participants will complete an Oxytocin Side Effect Checklist (OTSE), a list of 21 possible side effects [37] and the opportunity to report any other adverse effects, after each MIGT session. In addition, participants will be asked after each session to guess whether they have received oxytocin or placebo.

\section{Substance use data collection}

A urine sample will be collected at each study visit. A point-of-care, Clinical Laboratory Improvement Amendments (CLIA)-waived, 10-panel, Toxicology iCup Dx drug screen (Alere Inc., Waltham, MA, USA) will be used to screen samples for methamphetamine and other common substances of abuse.

\section{Audiovisual data collection}

Audio and video of each 90-min MIGT session will be recorded. The audio recording will be captured using the Blue Yeti USB omnidirectional microphone (Bluemic, Westlake Village, CA, USA) and recorded using Audacity audio software (Version 2.1.3, 2017) at a sample rate of $48,000 \mathrm{~Hz}$. Each co-facilitator and group member will be video recorded individually using a Google Nexus 7 Tablet (Google, Menlo Park, CA, USA) equipped with a 5.0-MP camera and recorded at a $1280 \times 720$ resolution and 30 frames per second.

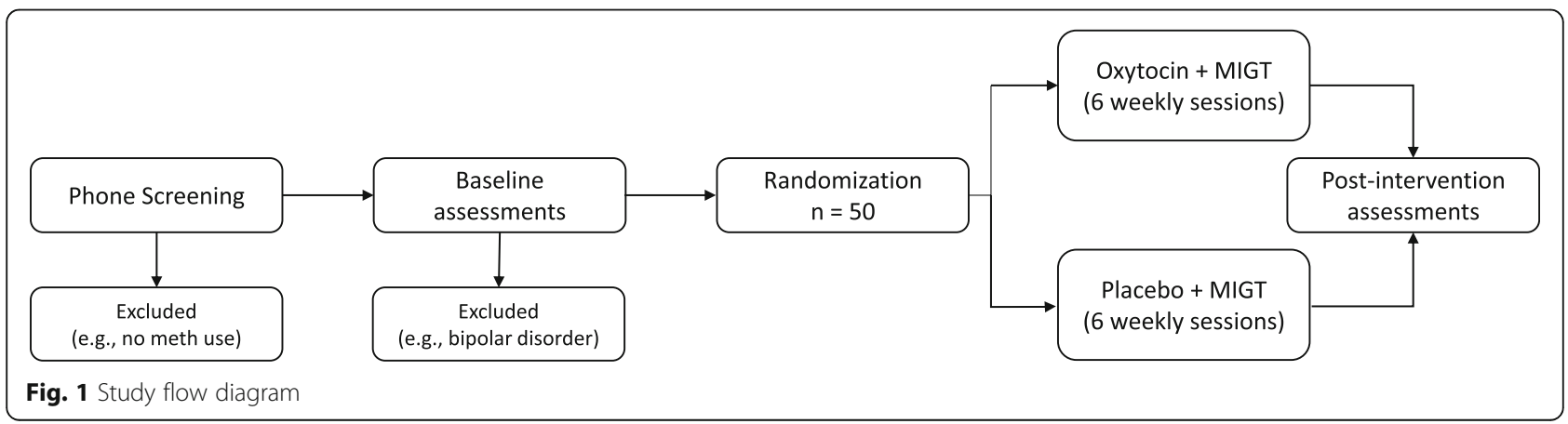




\section{Psychophysiology data collection}

Participants and co-facilitators will each be equipped with a Zephyr ${ }^{\text {ra }}$ BioHarness v3.0 (Zephyr Technology, Auckland, New Zealand), wearable, wireless, psychophysiology data collection equipment. Once a clear signal is established, participants will be comfortable seated for a silent, 5-min baseline physiology recording. The Zephyr ${ }^{\mathrm{Tm}}$ TEAM System using OmniSense Software (Version 4.2.4) will record a continuous electrocardiogram (sampled at $250 \mathrm{~Hz}$ ), respiratory rate, temperature, and three-axis accelerometry to measure posture and activity level throughout each 90-min MIGT session.

Psychophysiology data will be pre-processed using MindWare HRV software (v3.1.2, MindWare Technologies, Ltd., Gahanna, OH, USA). Artifacts will be identified via MindWare's dual MAD/MED and IBI Min/Max artifact detection algorithms derived from established strategy [65] and then processed manually. High-frequency heart rate variability (HF-HRV) is used as an indicator of parasympathetic nervous system activity and a primary psychophysiological variable of interest with regard to human social behavior. HRV is reduced in methamphetamine users when compared to matched healthy controls [66], and oxytocin has been previously shown to increase HRV via variable changes of increased HF-HRV and decreased Detrended Fluctuation Analysis (DFA-1), which measures how "self-similar" the data are [67]. Evidence suggests that autonomic cardiac control may moderate the relationship between oxytocin and social behavior, and HRV may play a key role in psychiatric patient response in treatment trials of oxytocin [68].

\section{Self-assessment measures}

Participants will complete self-assessment measures on Google Nexus 7 Tablets via Research Electronic Data Capture (REDCap), an online data capture tool, hosted by the University of California, San Francisco. At the initial visit, participants will be asked their preferred term for methamphetamine, and all future references to the drug in self-assessment questionnaires will use the individual respondent's preferred term. The timing of administration of self-assessment measures is shown in Fig. 2.

\section{Social and group cohesion measures}

1.1 The Group Questionnaire (GQ) [69], a 30-item measure of the quality of the therapeutic relationships in a group setting

1.2 The Social Provisions Scale (SPS) [70], a 24-item measure of the degree to which respondents' social relationships provide various dimensions of support

1.3 The Inclusion of Others in the Self (IOS) [71], a measure assessing perceived interpersonal connectedness to various "others" for which respondents choose one in a series of images of increasingly overlapping circles. The current study measures participants' relationships with: methamphetamine, methamphetamine-using communities, the LBGTQ community, their most intimate relationship, and their family of origin. The final administration of this questionnaire also asks about their relationship with their MIGT cohort for the study

1.4 The Sexual Risk-Taking Behavior (SRTB) questionnaire $[9,72]$ will be used to conduct a structured interview to assess risky sexual behaviors over the past 6 weeks. This measure asks the same questions regarding sex while sober and sex while under the influence of methamphetamine

2. Stress reactivity measures

2.1 The Six-Item State-Trait Anxiety Inventory Short Form (STAI-6) [73], a validated measure of the three highest anxiety-present and three highest anxiety-absent items from the state portion of the full State-Trait Anxiety Inventory [74]

\section{Substance use measures}

3.1 The Methamphetamine Craving QuestionnaireBrief (MCQ-Br), adapted from the Stimulant Craving Questionnaire-Brief [75], a 10-item measure of methamphetamine craving using a 7-point Likert scale

3.2 Self-reported methamphetamine use as measured by a Timeline Follow Back (TLFB), self-administered in our protocol [76], an assessment of daily use estimates for alcohol and other substances over the past 7 days [77]

3.3 The Readiness to Change Questionnaire (RTCQ) [78], adapted for methamphetamine users, is a 12-item measure based on the stagesof-change model [79]

Psychometric variables, including sociodemographic and diagnostic measures described above, that are pertinent to the unique combination of MUD, MIGT, and oxytocin administration, will be collected during the initial screening visit. Additional variables will include the following: The Experiences in Close Relationship Scale Short Form (ECR-S) [80], which is a 12-item measure of the construct of adult attachment, resulting in scores for attachment anxiety and attachment avoidance. For this study, we will substitute the term "romantic" for "intimate," which we defined as "emotional closeness, including close family relationships and/or romantic relationships." The Adverse Childhood Experiences (ACE) Questionnaire [81] is a 10-item measure of childhood experiences of abuse and neglect. ACE scores have a strong graded relationship to the risk of developing and maintaining 


\begin{tabular}{|c|c|c|c|c|c|c|c|c|c|c|c|c|c|c|}
\hline & \multicolumn{14}{|c|}{ Time of measurement ${ }^{*}$} \\
\hline & \multirow[t]{2}{*}{ BL } & \multirow[t]{2}{*}{$\mathbf{0}$} & \multicolumn{2}{|c|}{1} & \multicolumn{2}{|c|}{2} & \multicolumn{2}{|c|}{3} & \multicolumn{2}{|c|}{4} & \multicolumn{2}{|c|}{5} & \multicolumn{2}{|c|}{6} \\
\hline & & & Pre & Post & Pre & Post & Pre & Post & Pre & Post & Pre & Post & Pre & Post \\
\hline \multicolumn{15}{|l|}{ Enrollment } \\
\hline Eligibility Screen & $\mathrm{X}$ & & & & & & & & & & & & & \\
\hline Informed Consent & $\mathrm{X}$ & & & & & & & & & & & & & \\
\hline Medical Screen & $\mathrm{X}$ & & & & & & & & & & & & & \\
\hline Allocation & & $\mathrm{x}$ & & & & & & & & & & & & \\
\hline \multicolumn{15}{|l|}{ Assessments } \\
\hline Sociodemographic & $\mathrm{x}$ & & & & & & & & & & & & & \\
\hline Kinsey Scale & $\mathrm{x}$ & & & & & & & & & & & & & \\
\hline MINI & $\mathrm{X}$ & & & & & & & & & & & & & \\
\hline ASI-Lite & $\mathrm{X}$ & & & & & & & & & & & & & \\
\hline $\begin{array}{l}\text { SCID-5, Suicide } \\
\text { Assessment }\end{array}$ & $\mathrm{X}$ & & & & & & & & & & & & & \\
\hline ACE Questionnaire & $\mathrm{X}$ & & & & & & & & & & & & & \\
\hline ECR-S & $\mathrm{x}$ & & & & & & & & & & & & & \\
\hline STAI (full) & $\mathrm{X}$ & & & & & & & & & & & & & \\
\hline MCQ-Br & $\mathrm{X}$ & & $\mathrm{X}$ & $\mathrm{X}$ & $\mathrm{x}$ & $\mathrm{X}$ & $\mathrm{X}$ & $\mathrm{X}$ & $\mathrm{x}$ & $\mathrm{X}$ & $\mathrm{X}$ & $\mathrm{X}$ & $\mathrm{X}$ & $\mathrm{x}$ \\
\hline RTCQ & $\mathrm{x}$ & & & & & & & & & & & & & $\mathrm{X}$ \\
\hline TLFB & & & $\mathrm{X}$ & & $\mathrm{x}$ & & $\mathrm{x}$ & & $\mathrm{x}$ & & $\mathrm{x}$ & & $\mathrm{x}$ & \\
\hline GQ & & & & $\mathrm{X}$ & & $\mathrm{X}$ & & $\mathrm{X}$ & & $\mathrm{X}$ & & $\mathrm{X}$ & & $\mathrm{X}$ \\
\hline IOS & $\mathrm{x}$ & & & & & & & & & & & & & $\mathrm{x}$ \\
\hline OTSE & & & & $\mathrm{X}$ & & $\mathrm{X}$ & & $\mathrm{x}$ & & $\mathrm{X}$ & & $\mathrm{x}$ & & $\mathrm{x}$ \\
\hline STAI-6 & & & $\mathrm{X}$ & $\mathrm{X}$ & $\mathrm{x}$ & $\mathrm{X}$ & $\mathrm{X}$ & $\mathrm{x}$ & $\mathrm{x}$ & $\mathrm{X}$ & $\mathrm{x}$ & $\mathrm{x}$ & $\mathrm{X}$ & $\mathrm{x}$ \\
\hline SPS & $\mathrm{X}$ & & & & & & & & & & & & & $\mathrm{x}$ \\
\hline SRTB Questionnaire & $\mathrm{X}$ & & & & & & & & & & & & & $\mathrm{X}$ \\
\hline $\begin{array}{l}\text { *Intranasal study drug } \\
\text { administration and } \mathrm{OE}\end{array}$ & InIst & & & 11 & - & 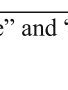 & & U & & $\pi$ & & $\tau_{1}$ & $\mathrm{dr}$ & \\
\hline
\end{tabular}

substance use disorders [82] and modify the relationship between intranasally administered oxytocin and cortisol reactivity in stimulant users [31]. The State-Trait Anxiety Inventory (STAI) [74] is a 40-item measure; 20 items assess for state anxiety and 20 items assess for trait anxiety. Lastly, subsections of the Addiction Severity Index-Lite (ASI-Lite) [83] will be used to assess quantity of substance use in the past 30 days as well as lifetime use patterns.

\section{Data management}

All electronic data will be stored on encrypted hard drives or password-protected computers. Hard copies of any data will be kept in locked filing cabinets in a secure office. All questionnaire data will be de-identified. An independent data monitoring committee (DMC) will review accumulated data on a regular basis. Additionally, the study's Institutional Review Board (IRB) will monitor the trial and conduct an audit once per year.

\section{Data Analysis Plan}

Descriptive statistics will be used for demographic information and other baseline characteristics. Our dichotomous primary outcome measure (in attendance/absent) will be compared between oxytocin and placebo treatment conditions using generalized estimating equations to accommodate for correlations among the observations 
originating from the same participant and correct for interdependence resulting from MIGT cohort membership. Secondary outcomes collected at each MIGT session consist of group cohesion as measured by the GQ, self-reported anxiety as measured by the STAI-6, psychophysiological measures (including heart rate, HF-HRV, and temperature), methamphetamine craving as measured by the MCQ-Br, and urine drug screen. Given the exploratory nature of this novel study design, we will use descriptive statistics and estimate Cohen's $d$ effect sizes for secondary outcomes. Effect sizes will be calculated by subtracting the mean change in the oxytocin group from the mean change in the placebo group and dividing by the pooled baseline standard deviation. If there is substantial missing data, we also will consider using mixed linear models or multiple-imputation techniques to estimate mean change values in each treatment group with greater accuracy. Additional exploratory outcome measures collected at two timepoints, baseline and after the final MIGT session, consist of the SRTB, SPS, IOS, and RTCQ and will be processed using the same methodology. Results of secondary outcomes will be considered exploratory, and further confirmatory studies would be needed to confirm the results. ECR-S, ACE, STAI, and subsections of the ASI-Lite, along with baseline measurements of the SPS, IOS, SRTB, and RTCQ, will be explored as potential predictors of oxytocin response using Pearson's correlation coefficients.

In addition to utilizing psychophysiology measures recorded during MIGT sessions as a secondary outcome variable in our main data analysis approach, we will utilize models designed to explore physiological synchrony, contagion, and other aspects of shared physiological states [84].

\section{Discussion}

The high prevalence of MUD among MSM leads to significant health disparities, including increased risk for HIV seroconversion. Currently, no psychopharmacological agent is FDA-approved for the treatment of MUD. This investigation represents the first randomized clinical trial to administer the social peptide, oxytocin, to individuals with MUD. Data from this study should inform further development of oxytocin's role in psychopharmacological-psychosocial combination treatment. Outcomes aim to further elucidate the potential mechanisms of OE-MIGT for MUD. Overall, this study aims to address methamphetamine use, treatment engagement, and stress reactivity in a difficult-to-treat population for whom current attrition rates are high (Additional file 1).

\section{Limitations and future directions}

The current study will only include men who identify as having sex with men; therefore, results may not generalize to other genders and sexual orientations. There may be further selection bias regarding the motivation and engagement of participants who choose to take part in our study protocol. Furthermore, studies with substance use disorder populations often must deal with missing data from attrition. Our self-report measures increase the risk of reporting bias, although objective measures of psychophysiology will also be examined. Lastly, group therapy studies present inherent complications regarding statistical analyses. We will take these factors into account, although likely at the expense of statistical power. Despite these limitations, this study has many novel features and effect sizes will contribute to ongoing research. Future goals involve the further development of oxytocin-enhanced psychotherapy and expanding this treatment modality to other patient populations.

\section{Trial status}

Protocol version 1.0. Recruitment started on 27 March 2017 and is estimated to end around 31 December 2018.

\section{Additional file}

Additional file 1: Standard Protocol Items: Recommendations for Interventional Trials (SPIRIT) 2013 Checklist: recommended items to address in a clinical trial protocol and related documents. (DOC $121 \mathrm{~kb}$ )

\section{Abbreviations}

ACE: Adverse Childhood Experiences; AIDS: Acquired immune deficiency syndrome; ANOVA: Analysis of variance; ASI-Lite: Addiction Severity IndexLite; CLIA: Clinical Laboratory Improvement Amendments; DFA-1: Detrended Fluctuation Analysis; ECR-S: Experiences in Close Relationships-Short; GQ: Group Questionnaire; HF-HRV: High-frequency heart rate variability; HIV: Human immunodeficiency virus; HRV: Heart rate variability; IOS: Inclusion of Others in the Self; MCQ-Br: Meth Craving Questionnaire-Brief; MI: Motivational interviewing; MIGT: Motivational interviewing group therapy; MINI: Mini International Neuropsychiatric Interview;

MITI: Motivational Interviewing Treatment Integrity; MSM: Men who have sex with men; MUD: Methamphetamine use disorder; OE-MIGT: Oxytocinenhanced motivational interviewing group therapy; OTSE: Oxytocin Side Effect Checklist; RTCQ: Readiness to Change Questionnaire; SCID5: Structured Clinical Interview for DSM-5; SPS: Social Provisions Scale; SRTB: Sexual Risk-Taking Behavior questionnaire; STAI: State-Trait Anxiety Inventory; STAI-6: Six-item State-Trait Anxiety Inventory; TLFB: Timeline Follow Back; US: United States

\section{Acknowledgements}

We acknowledge the support of Dr. Jim Dilley and the UCSF Alliance Health Project, Dr. Adam Carrico, Rick Andrews and the Positive Reinforcement Opportunity Project (PROP), and the San Francisco AIDS Foundation.

\section{Funding}

This pilot study is primarily funded by the UCSF Academic Senate via the UCSF Resource Allocation Program. Project: 7501159 and Subproject:

7504319. Additional funding provided by the Department of Veterans Affairs Clinical Science Research and Development. Federal Award Identification Number IK2CX001495. Neither funding bodies had any influence on the trial.

Availability of data and materials

Individual participant data and the OE-MIGT treatment manual will be available from the corresponding author on reasonable request. 


\section{Authors' contributions}

CSS conceptualized and designed the study and will manage data collection, analysis, and dissemination. JMM co-developed the facilitator's manual. EH developed the protocol for psychophysiology measurement. SMM is the project coordinator and is responsible for study implementation. BB trained MIGT providers and will manage MI fidelity. JDW provided mentorship on study design and implementation. All authors contributed to writing, revising, and approving the final manuscript.

\section{Ethics approval and consent to participate}

This study established ethical approval from the Institutional Review Board (IRB) at the University of California, San Francisco Human Research Protection Program on 6 November 2016 (\#16-20,360).

\section{Consent for publication}

Not applicable.

\section{Competing interests}

The authors declare that they have no competing interests.

\section{Publisher's Note}

Springer Nature remains neutral with regard to jurisdictional claims in published maps and institutional affiliations.

\section{Author details}

1 University of California, San Francisco, San Francisco VA Medical Center, San Francisco, CA, USA. ${ }^{2}$ Palo Alto University, Palo Alto, CA, USA. ${ }^{3}$ University of California, San Francisco, CA, USA. ${ }^{4}$ University of California, San Francisco School of Medicine, San Francisco, CA, USA.

\section{Received: 19 March 2018 Accepted: 28 January 2019}

\section{Published online: 21 February 2019}

\section{References}

1. Scott JC, Woods SP, Matt GE, Meyer RA, Heaton RK, Atkinson JH, Grant I. Neurocognitive effects of methamphetamine: a critical review and metaanalysis. Neuropsychol Rev. 2007. https://doi.org/10.1007/s11065-007-9031-0.

2. United Nations Office on Drugs and Crime. Amphetamines and Ecstasy 2011 Global ATS Assessment; 2011. Retrieved from http://www.unodc.org/ documents/ATS/ATS_Global_Assessment_2011.pdf. Accessed Mar 2019.

3. Winstock A, Barratt M, Ferris J, Maier L. Global Drug Survey 2017: Global Overview and Highlights N > 115,000; 2017.

4. Centers for Disease Control. Methamphetamine use and risk for HIV/AIDS Fact Sheet; 2007.

5. Gruenewald PJ, Ponicki WR, Remer LG, Waller LA, Zhu L, Gorman DM. Mapping the spread of methamphetamine abuse in California from 1995 to 2008. Am J Public Health. 2013;103(7):1262-70. https://doi.org/10.2105/AJPH. 2012.300779.

6. Substance Abuse and Mental Health Services Administration. Results from the 2016 National Survey on Drug Use and Health (HHS Publication No. SMA 17-5044, NSDUH Series H-52). 2017. 1-78.

7. Brackins T, Brahm NC, Kissack JC. Treatments for methamphetamine abuse: a literature review for the clinician. J Pharm Pract. 2011;24(6):541-50. https:// doi.org/10.1177/0897190011426557.

8. Brensilver M, Heinzerling KG, Shoptaw S. Pharmacotherapy of amphetamine-type stimulant dependence: an update. Drug Alcohol Rev. 2013. https://doi.org/10.1111/dar.12048.

9. Carrico AW, Flentje A, Gruber VA, Woods WJ, Discepola MV, Dilworth SE, et al. Community-based harm reduction substance abuse treatment with methamphetamine-Using men who have sex with men. J Urban Health. 2014;91(3):555-67. https://doi.org/10.1007/s11524-014-9870-y.

10. Lee NK, Rawson RA. A systematic review of cognitive and behavioural therapies for methamphetamine dependence. Drug Alcohol Rev. 2008. https://doi.org/10.1080/09595230801919494.

11. Manning V, Garfield JB, Best D, Berends L, Room R, Mugavin J, et al. Substance use outcomes following treatment: findings from the Australian Patient Pathways Study. Aust N Z J Psychiatry. 2016. https://doi.org/10.1177/ 0004867415625815

12. Smout MF, Longo M, Harrison S, Minniti R, Wickes W, White JM. Psychosocial treatment for methamphetamine use disorders: a preliminary randomized controlled trial of cognitive behavior therapy and acceptance and commitment therapy. Subst Abus. 2010;31(2):98-107. https://doi.org/10. 1080/08897071003641578.

13. Brecht $M-L$, Herbeck D. Time to relapse following treatment for methamphetamine use: a long-term perspective on patterns and predictors. Drug Alcohol Depend. 2014;139:18-25. https://doi.org/10. 1016/j.drugalcdep.2014.02.702.

14. Scott CK. A replicable model for achieving over $90 \%$ follow-up rates in longitudinal studies of substance abusers. Drug Alcohol Depend. 2004; $74: 21-36$

15. Cook R, Quinn B, Heinzerling K, Shoptaw S. Dropout in clinical trials of pharmacological treatment for methamphetamine dependence: the role of initial abstinence. Addiction. 2017;112(6):1077-85. https://doi.org/10. 1111/add.13765.

16. Homer BD, Solomon TM, Moeller RW, Mascia A, DeRaleau L, Halkitis PN. Methamphetamine abuse and impairment of social functioning: a review of the underlying neurophysiological causes and behavioral implications. Psychol Bull. 2008;134(2):301-10. https://doi.org/10.1037/ 0033-2909.134.2.301.

17. Uhlmann A, Ipser JC, Wilson D, Stein DJ. Social cognition and aggression in methamphetamine dependence with and without ahistory of psychosis. Metab Brain Dis. 2017. https://doi.org/10.1007/s11011-017-0157-3 [Epub ahead of print].

18. Kim Y, Kwon D, Chang Y. Impairments of facial emotinon recognition and theory of mind in methamphetamine abusers. Psychiatry Res. 2011;186(1). https://doi.org/10.1016/j.psychres.2010.06.027.

19. Payer DE, Liberman MD, Monterosso JR, Xu J, Fong TW, London ED. Differences in cortical activity between methamphetamine-dependent and healthy individuals performing a facial affect matching task. Drug Alcohol Depend. 2008;93(1-2):93-102.

20. Obert JL, McCann MJ, Marinelli-Casey P, Weiner A, Minksy S, Brethen P, Rawson R. The matrix model of outpatient stimulant abuse treatment history and description. J Psychoactive Drugs. 2000;32(2):157-64.

21. Flores PJ. Group psychotherapy with addicted populations: an integration of twelve-step and psychodynamic theory. 3rd ed. New York: Routledge; 2007.

22. Westenbroek C, Perry AN, Jagannathan L, Becker JB. Effect of social housing and oxytocin on the motivation to self-administer methamphetamine in female rats. In: Physiology and Behavior; 2017. https://doi.org/10.1016/j. physbeh.2017.10.020.

23. Rose ME, Grant JE. Pharmacotherapy for methamphetamine dependence: a review of the pathophysiology of methamphetamine addiction and the theoretical basis and efficacy of pharmacotherapeutic interventions. Ann Clin Psychiatry. 2008. https://doi.org/10.1080/10401230802177656.

24. Gordon I, Martin C, Feldman R, Leckman JF. Oxytocin and social motivation. Dev Cognitive Neurosci. 2011. https://doi.org/10.1016/j.dcn.2011.07.007.

25. Meyer-Lindenberg A, Domes G, Kirsch P, Heinrichs M. Oxytocin and vasopressin in the human brain: social neuropeptides for translational medicine. Nat Rev Neurosci. 2011. https://doi.org/10.1038/nrn3044.

26. Olff M, Frijling JL, Kubzansky LD, Bradley B, Ellenbogen MA, Cardoso C, et al. The role of oxytocin in social bonding, stress regulation and mental health: an update on the moderating effects of context and interindividual differences. Psychoneuroendocrinology. 2013;38(9):1883-94. https://doi.org/ 10.1016/j.psyneuen.2013.06.019

27. Lee MR, Rohn MCH, Tanda G, Leggio L. Targeting the oxytocin system to treat addictive disorders: rationale and progress to date. CNS Drugs. 2016. https://doi.org/10.1007/s40263-016-0313-z.

28. Sarnyai Z, Kovács GL. Oxytocin in learning and addiction: from early discoveries to the present. Pharmacol Biochem Behav. 2014. https://doi.org/ 10.1016/j.pbb.2013.11.019.

29. Buisman-Pijlman FTA, Sumracki NM, Gordon JJ, Hull PR, Carter CS, Tops M Individual differences underlying susceptibility to addiction: role for the endogenous oxytocin system. Pharmacol Biochem Behav. 2014. https://doi. org/10.1016/j.pbb.2013.09.005.

30. Shamay-Tsoory SG, Abu-Akel A. The social salience hypothesis of oxytocin. Biol Psychiatry. 2016. https://doi.org/10.1016/j.biopsych.2015.07.020.

31. Flanagan JC, Baker NL, MCRae-Clark AL, Brady KT, Moran-Santa Maria MM. Effects of adverse childhood experiences on the association between intranasal oxytocin and social stress reactivity among individuals with cocaine dependence. Psychiatry Res. 2015;229(1-2):94-100. https://doi.org/ 10.1016/j.psychres.2015.07.064

32. Heinrichs M, Baumgartner T, Kirschbaum C, Ehlert U. Social support and oxytocin interact to suppress cortisol and subjective responses to 
psychosocial stress. Biol Psychiatry. 2003;54(12):1389-98. https://doi.org/10. 1016/S0006-3223(03)00465-7.

33. Sippel LM, Allington CE, Pietrzak RH, Harpaz-Rotem I, Mayes LC, Olff M. Oxytocin and stress-related disorders: neurobiological mechanisms and treatment opportunities. Chronic Stress. 2017;1:247054701668799. https:// doi.org/10.1177/2470547016687996.

34. Tops M, Koole SL, ljzerman H, Buisman-Pijlman FTA. Why social attachment and oxytocin protect against addiction and stress: insights from the dynamics between ventral and dorsal corticostriatal systems. Pharmacol Biochem Behav. 2014;1 19:39-48. https://doi.org/10.1016/j.pbb.2013.07.015.

35. Norman GJ, Cacioppo JT, Morris JS, Karelina K, Malarkey WB, Devries AC, Berntson GG. Selective influences of oxytocin on the evaluative processing of social stimuli. J Psychopharmacol. 2011;25(10):1313-9. https://doi.org/10. 1177/0269881110367452.

36. Striepens N, Kendrick KM, Hanking V, Landgraf R, Wüllner U, Maier W, Hurlemann R. Elevated cerebrospinal fluid and blood concentrations of oxytocin following its intranasal administration in humans. Sci Rep. 2013;3. https://doi.org/10.1038/srep03440

37. MacDonald E, Dadds MR, Brennan JL, Williams K, Levy F, Cauchi AJ. A review of safety, side-effects and subjective reactions to intranasal oxytocin in human research. Psychoneuroendocrinology. 2011. https://doi.org/10.1016/j. psyneuen.2011.02.015.

38. Baracz S, Parker L, Suraev A, Everett N, Goodchild A, Cornish J. Chronic methamphetamine self-administration dysregulates oxytocin plasma levels and oxytocin receptor fibre density in the nucleus accumbens core and subthalamic nucleus of the rat. J Neuroendocrinol. 2015;28. https://doi.org/ 10.1111/jne.12337.

39. Krasnova IN, Gerra MC, Walther D, Jayanthi S, Ladenheim B, McCoy MT, et al. Compulsive methamphetamine taking in the presence of punishment is associated with increased oxytocin expression in the nucleus accumbens of rats. Sci Rep. 2017;7(1). https://doi.org/10.1038/s41598-017-08898-8.

40. Zanos P, Wright SR, Georgiou P, Yoo JH, Ledent C, Hourani SM, et al. Chronic methamphetamine treatment induces oxytocin receptor upregulation in the amygdala and hypothalamus via an adenosine A2A receptor-independent mechanism. Pharmacol Biochem Behav. 2014;1 19:729. https://doi.org/10.1016/.jpbb.2013.05.009.

41. Carson DS, Bosanquet DP, Carter CS, Pournajafi-Nazarloo H, Blaszczynski A, McGregor IS. Preliminary evidence for lowered basal cortisol in a naturalistic sample of methamphetamine polydrug users. Exp Clin Psychopharmacol. 2012;20(6):497-503. https://doi.org/10.1037/a0029976.

42. Baracz SJ, Cornish JL. The neurocircuitry involved in oxytocin modulation of methamphetamine addiction. Front Neuroendocrinol. 2016;43:1-18. https:// doi.org/10.1016/j.yfrne.2016.08.001.

43. Baracz SJ, Everett NA, McGregor IS, Cornish JL. Oxytocin in the nucleus accumbens core reduces reinstatement of methamphetamine-seeking behaviour in rats. Addict Biol. 2016;21 (2):316-25. https://doi.org/10.1111/adb.12198.

44. Carson DS, Cornish JL, Guastella AJ, Hunt GE, McGregor IS. Oxytocin decreases methamphetamine self-administration, methamphetamine hyperactivity, and relapse to methamphetamine-seeking behaviour in rats. Neuropharmacology. 2010;58(1):38-43. https://doi.org/10.1016/j. neuropharm.2009.06.018.

45. Carson DS, Hunt GE, Guastella AJ, Barber L, Cornish JL, Arnold JC, et al. Systemically administered oxytocin decreases methamphetamine activation of the subthalamic nucleus and accumbens core and stimulates oxytocinergic neurons in the hypothalamus. Addict Biol. 2010;15(4):448-63. https://doi.org/10.1111/j.1369-1600.2010.00247.x.

46. Ferland $\mathrm{CL}$, Reichel CM, McGinty JF. Effects of oxytocin on methamphetamine-seeking exacerbated by predator odor pre-exposure in rats. Psychopharmacology. 2016;233(6):1015-24. https://doi.org/10.1007/ s00213-015-4184-7.

47. Han WY, Du P, Fu SY, Wang F, Song M, Wu CF, et al. Oxytocin via its receptor affects restraint stress-induced methamphetamine CPP reinstatement in mice: involvement of the medial prefrontal cortex and dorsal hippocampus glutamatergic system. Pharmacol Biochem Behav. 2014;119:80-7. https://doi.org/10.1016/j.pbb.2013.11.014.

48. Carson DS, Cornish JL, Guastella AJ, Hunt GE, McGregor IS. Oxytocin decreases methamphetamine self-administration, methamphetamine hyperactivity, and relapse to methamphetamine-seeking behaviour in rats. Neuropharmacology. 2010;58(1):38-43. https://doi.org/10.1016/.j.neuropharm.2009.06.018.

49. Hicks C, Cornish JL, Baracz SJ, Suraev A, McGregor IS. Adolescent pretreatment with oxytocin protects against adult methamphetamine-seeking behavior in female rats. Addict Biol. 2016;21(2):304-15. https://doi.org/10. 1111/adb.12197.

50. Baracz SJ, Rourke PI, Pardey MC, Hunt GE, McGregor IS, Cornish JL. Oxytocin directly administered into the nucleus accumbens core or subthalamic nucleus attenuates methamphetamine-induced conditioned place preference. Behav Brain Res. 2012;228(1):185-93. https://doi.org/10.1016/j. bbr.2011.11.038.

51. Carson DS, Hunt GE, Guastella AJ, Barber L, Cornish JL, Arnold JC, et al. Systemically administered oxytocin decreases methamphetamine activation of the subthalamic nucleus and accumbens core and stimulates oxytocinergic neurons in the hypothalamus. Addict Biol. 2010;15(4):448-63. https://doi.org/10.1111/j.1369-1600.2010.00247.x.

52. Sherman BJ, Baker NL, McRae-Clark AL. Effect of oxytocin pretreatment on cannabis outcomes in a brief motivational intervention. Psychiatry Res. 2017 : 249318-20. https://doi.org/10.1016/j.psychres.2017.01.027.

53. Miller WR, Rollnick S. Motivational interviewing: helping people change (3rd ed). New York: The Guilford Press; 2013.

54. Wagner C, Ingersoll K. Motivational interviewing in groups. New York: The Guilford Press; 2013

55. Center on Alcoholism Substance Use and Addictions. Coding Instruments: Motivational Interviewing Treatment Integrity (MITI) Code 4.2. 2016.

56. Borsari B, Carey KB. Two brief alcohol interventions for mandated college students. Psychol Addict Behav. 2005;19(3):296-302.

57. Borsari B, Hustad JTP, Mastroleo NR, et al. Addressing alcohol use and problems in mandated college students: a randomized clinical trial using stepped care. J Consult Clin Psychol. 2012;80(6):1062-74.

58. Stauffer CS, Musinipally V, Suen A, Lynch KL, Shapiro B, Woolley JD. A twoweek pilot study of intranasal oxytocin for cocaine-dependent individuals receiving methadone maintenance treatment for opioid use disorder. Addict Res Theory. 2016;24(6). https://doi.org/10.3109/16066359.2016. 1173682.

59. Hoge EA, Anderson E, Lawson EA, Bui E, Fischer LE, Khadge SD, et al. Gender moderates the effect of oxytocin on social judgments. Human Psychopharmacol. 2014;29(3):299-304. https://doi.org/10.1002/hup.2402.

60. Thienel M, Heinrichs M, Fischer S, Ott V, Born J, Hallschmid M. Oxytocin's impact on social face processing is stronger in homosexual than heterosexual men. Psychoneuroendocrinology. 2014;39:194-203. https://doi. org/10.1016/j.psyneuen.2013.09.013.

61. Weinrich JD. The Kinsey Scale in biology, with a note on Kinsey as a biologist. In: DP MW, Sanders SA, Reinisch JM, editors. Homosexuality/ heterosexuality: concepts of sexual orientation. New York: Oxford University Press; 1990. p. 115-37.

62. Sheehan D, Janavs J, Baker R, Sheehan KH, Knapp E, Sheehan M. Mini International Neuropsychiatric Interview - version 7.0.0; 2015 [Measurement instrument] Retrieved March 2018 from www.harmresearch.org.

63. First MB, Williams JBW, Karg RS, Spitzer RL. Structured Clinical Interview for DSM-5-Clinical Version (SCID-5-CV). Arlington: American Psychiatric Association; 2015

64. Guastella AJ, Hickie IB, McGuinness MM, Otis M, Woods EA, Disinger HM, et al. Recommendations for the standardisation of oxytocin nasal administration and guidelines for its reporting in human research Psychoneuroendocrinology. 2013;38(5):612-25.

65. Berntson GG, Quigley KS, Jang JF, Boysen ST. An approach to artifact identification: application to heart period data. Psychophysiology. 1990; 27(5):586-98. https://doi.org/10.1111/j.1469-8986.1990.tb01982.x.

66. Henry BL, Minassian A, Perry W. Effect of methamphetamine dependence on heart rate variability. Addict Biol. 2012;17(3):648-58. https://doi.org/10. 1111/j.1369-1600.2010.00270.x.

67. Kemp AH, Quintana DS, Kuhnert RL, Griffiths K, Hickie IB, Guastella AJ. Oxytocin increases heart rate variability in humans at rest: implications for social approach-related motivation and capacity for social engagement. PLoS One. 2012;7(8). https://doi.org/10.1371/journal.pone.0044014.

68. Quintana DS, et al. A role for autonomic cardiac control in the effects of oxytocin on social behavior and psychiatric illness. Front Neurosci. 2013;7:48. https://doi.org/10.3389/fnins.2013.00048.

69. Krogel J, Burlingame G, Chapman C, Renshaw T, Gleave R, Beecher M, Macnair-Semands R. The Group Questionnaire: a clinical and empirically derived measure of group relationship. Psychother Res. 2013;23(3):344-54. https://doi.org/10.1080/10503307.2012.729868.

70. Cutrona C, Russell D. The provisions of social relationships and adaptation to stress. Adv Personal Relationships. 1983;1:37-67. 
71. Aron A, Aron EN, Smollan D. Inclusion of Other in the Self Scale and the Structure of Interpersonal Closeness. J Pers Soc Psychol. 1992;63(4):596-612.

72. Carrico AW, Gomez W, Siever MD, Discepola MV, Dilworth SE, Moskowitz JT. Pilot randomized controlled trial of an integrative intervention with methamphetamine-using men who have sex with men. Arch Sex Behav. 2015:44(7):1861-7. https://doi.org/10.1007/s10508-015-0505-5.

73. Marteau TM, Bekker $\mathrm{H}$. The development of a six-item short-form of the State Scale of the Spielberger State-Trait Anxiety Inventory (STAI). Br J Clin Psychol. 1992;31(Pt 3):301-6.

74. Spielberger CD, Gorsuch RL, Lushene R, Vagg PR, Jacobs GA. Manual for the State-Trait Anxiety Inventory. Palo Alto: Consulting Psychologists Press; 1983.

75. Northrup TF, Green C, Walker R, Greer TL, \& Trivedi, M. H. Stimulant craving Questionnaire-Brief. PsycTESTS. Northrup, Thomas F., University of Texas Medical School at Houston, Department of Family and Community Medicine, 6431 Fannin, JJL 328, Houston, Texas, United States, 77030. 2015. https://doi.org/10.1037/t38311-000.

76. Sobell LC, Brown J, Leo Gl, Sobell MB. The reliability of the Alcohol Timeline Followback when administered by telephone and by computer. Drug Alcohol Depend. 1996;42(1):49-54.

77. Hoeppner BB, Stout RL, Jackson KM, Barnett NP. How good is fine-grained Timeline Follow-back data? Comparing 30-day TLFB and repeated 7-day TLFB alcohol consumption reports on the person and daily level. Addict Behav. 2010;35(12):1138-43. https://doi.org/10.1016/j.addbeh.2010.08.013.

78. Heather N, Hönekopp J. A revised edition of the Readiness to Change Questionnaire [Treatment Version]. Addict Res Theory. 2008;16(5):421-33. https://doi.org/10.1080/16066350801900321.

79. Prochaska JO, DiClemente CC. Stages and processes of self-change of smoking: toward an integrative model of change. J Consult Clin Psychol. 1983:51(3):390-5. https://doi.org/10.1037/0022-006X.51.3.390.

80. Wei M, Russell DW, Mallinckrodt B, Vogel DL. The Experiences in Close Relationship Scale (ECR)-short form: reliability, validity, and factor structure. J Pers Assess. 2007;88(2):187-204. https://doi.org/10.1080/00223890701268041.

81. Felitti VJ, Anda RF, Nordenberg D, Williamson DF, Spitz AM, Edwards V, et al. Relationship of childhood abuse and household dysfunction to many of the leading causes of death in adults: the Adverse Childhood Experiences (ACE) study. Am J Prev Med. 1998;14(4):245-58. https://doi.org/10.1016/S07493797(98)00017-8

82. Dube SR, Felitti VJ, Dong M, Chapman DP, Giles WH, Anda RF. Childhood abuse, neglect, and household dysfunction and the risk of illicit drug use: the adverse childhood experiences study. Pediatrics. 2003;111(3):564-72.

83. McLellan AT, Cacciola JS, Zanis D. The Addiction Severity Index-"Lite"(ASI"Lite"). Center for the Studies of Addiction. Philadelphia: University of Pennsylvania/Philadelphia VA Medical Center; 1997.

84. Thorson KR, West TV, Mendes WB. Measuring physiological influence in dyads: a guide to designing, implementing, and analyzing dyadic physiological studies. Psychol Methods. 2018;23(4):595-616.

Ready to submit your research? Choose BMC and benefit from:

- fast, convenient online submission

- thorough peer review by experienced researchers in your field

- rapid publication on acceptance

- support for research data, including large and complex data types

- gold Open Access which fosters wider collaboration and increased citations

- maximum visibility for your research: over $100 \mathrm{M}$ website views per year

At $\mathrm{BMC}$, research is always in progress.

Learn more biomedcentral.com/submissions 